\title{
Upaya Meningkatkan Hasil Belajar Passing Bawah Permainan Bola Voli Melalui Media Balon
}

\section{Efforts To Improve The Learning Outcomes Of Volleyball Passing Using Balloon Media}

\author{
Jumari $^{1)}$, Siti Qomariah ${ }^{2)}$ \\ ${ }^{1)}$ SD Negeri 32 Singkawang, ${ }^{2)}$ SMP Negeri 1 Singkawang \\ Email: jumarislk@gmail.com, ${ }^{2}$ citycom36@gmail.com
}

\begin{tabular}{l}
\hline Info Artikel \\
\hline Sejarah Artikel: \\
Diterima \\
(April) (2021) \\
Disetujui \\
(Mei) (2021) \\
Dipublikasikan \\
(Mei) (2021 \\
\\
\\
Keywords: \\
Drill Training, \\
Hanging Ball Media, \\
Smash kedeng
\end{tabular}

Abstrak

Permasalahan yang terdapat pada peserta didik yaitu pada saat melakukan passing bola bawah tidak dapat dilakukan dengan baik. Tujuan penelitian ini yaitu meningkatkan kemampuan passing bawah, sampel pada penelitian ini peserta didik di SDN 13 Singkawang. Metode penelitian menggunakan metode penelitian tindakan kelas, objek penelitan ini yaitu guru yang bekerja sama dengan peserta didik kelas $V$ yang berjumlah 25 peserta didik. Hasil penelitian yang ditemukan bahwa pada siklus I terdapat 64\% siswa yang tuntas dengan jumlah 16 siswa dari 25 siswa, kemudian dilanjutkan dengan siklus II yang menunjukan peningkatan ketuntasan siswa sebesar 92\% dengan jumlah 23 siswa dengan nilai rata-rata 76,4 dalam kemampuan teknik passing bawah. Dapat ditarik kesimpulan bahwa metode pembelajaran kreatif dengan menambahkan media balon dapat memberikan dampak positif bagi peserta didik dan meningkatkan motivasi dalam pembelajaran bola voli khususnya passing bawah.

Abstract

The problem found in students is that when passing the ball down, it cannot be done properly. The purpose of this study is to improve the ability to pass down, the sample in this study were students at SDN 13 Singkawang. The research method uses classroom action research methods, the object of this research is the teacher who works with the fifth-grade students, totaling 25 students. The results of the study found that in the first cycle there were $64 \%$ of students who completed with a total of 16 students from 25 students, then continued with the second cycle which showed an increase in student mastery by $92 \%$ with a total of 23 students with an average value of 76.4 in technical ability. bottom pass. It can be concluded that creative learning methods by adding balloon media can have a positive impact on students and increase motivation in volleyball learning, especially under passing.

(C) 2021 Pendidikan Jasmani, Universitas Tanjungpura

Alamat korespondensi

E-mail

Jl. Dusun damai RT. 2 RW. 2 Parit Baru Kec. Selakau

No Handphone

jumarislk@gmail.com 


\section{PENDAHULUAN}

Pendidikan jasmani dan olahraga merupakan pendidikan yang mana dalam pelaksanaannya menggunakan aktivitas fisik, untuk mendapatkan perubahan hasil dari holistik yang masuk dalam kualitas hidup individu, baik itu dari fisik, mental dan emosional individu (Olih Solihin, 2016). Dalam pendidikan jasmani dan olahraga harus mengenal yang namanya prinsipprinsip gerak. Yang mana dapat diketahui bahwa pengetahuan mengenal gerak dapat membantu peserta ddik dalam memahami bagaimana sebuah keterampilan dapat dimengerti sehingga pada tingkat yang tinggi. Melalui pendidikan jasmani dan olahraga akan mendapatkan pengalaman yang mana berkenaan dengan kreatifitas, memiliki inovatif, jelas bahwa memiliki keterampilan gerak, memiliki pola hidup yang sehat, pengetahuan serta pemahanan pada pembelajaran gerak manusia dan juga membentuk suatu kepribadian yang positif (Setia Lengkana, 2017).

Salah satu cabang olahraga permainan yaitu bola voli. Dapat diketahui bahwa untuk permainan bola voli sidah femiliar dikalangan masyarakat, bahwa sudah menyentuh di berbagai lapisan masyarakat. Dalam berbagai cabang olahraga, diketahui bahwa, untuk memainkan permainan harus memiliki teknik dasar, tidak terkecuali pada permainan bola voli, dalam memainkan bola voli memiliki teknik dasar tersendiri (Nanda Hanief, 2018) Namun secara umum yang dapat diketahui bahwa dalam pemainan bola voli, harus memiliki regu / tim pemain, kemudian, tidak terlepas juga harus memiliki kondisi fisik dan mental yang baik pada saat ingin memainkan permainan bola voli, mau hal tersebut hanya untuk berolahrga ataupun untuk sebuah pertandingan (Faozi, 2019).

Dalam mewujudkan terciptanya permainan bola voli yang baik, dalam hal ini peserta didik wajib untuk mengetahui serta memahami teknik dasar dalam bermain, kemudian dapat mengembangkan kemampuan gerak. Untuk pengembangan prestasi pada cabang olahraga bola voli maka diharapkan untuk mengikuti pelatihan serta pembinaan oleh profesional dalam bidangnya yaitu permainan bola voli (Rahmat, 2018).
Terdapat beberapa faktor yang dapat mempengaruhi tidak maksimalnya peserta didik dalam mendapatkan pembinaan dan pelatihan, yaitu salah satunya jika guru permainan bola voli tersebut tidak memiliki kreatifitas dalam memberikan pembinan dan pelatihan yang diikuti dengan perkembangan metode pembelajaran saat ini. Dalam hal ini terdapat faktor yang mana pada model pembelajaran yang tidak ktratif mengakibatkan situasi dan kondisi pembelajaran yang monoton dan tidak menarik (Hambali, 2016).

Dalam hal ini pembelaaran penjasorkes pada bidang cabang olahraga permainan bola voli di SDN 13 Singkawang Barat memiliki pembelajaran yang tidak maksimal dalam pengembangan peserta didik dalam cabang olahraga bola voli. Yang mana guru penjas di SDN 13 Singkawang, pada saat pembelajaran bola voli, peserta didik dibiarkan bermain dengan sendirinya tanpa memberi pembelajaran untuk mengetahui teknik-teknik dasar dalam memainkan permainan bola voli yang benar.

Modifikasi bola adalah salah satu cara untuk memberikan pengetahuan dalam memainkan bola voli khususnya pada saat ingin melakukan pasing bawah. Dengan ini, peneliti akan menggunakan modifikasi bola untuk melaksanakan penelitian. Yaitu dengan media bola balon. Yang mana metode ini akan berpengaruh pada kepercaya diri peserta didik dalam melakukan pasing bawah tanpa harus memikirkan bahwa tangan akan terasa sakit saat malukannya.

Kemudian, dari segi biaya menggunakan metode balon, lebih efektif dan murah yang mana balon itu sendiri mudah didapatkan. Dari lata belakang masalah yang telah dijabarkan diatas, maka peneliti dalam kesempatan ini akan meneliti "upaya meningkatkan hasil belajar passing bawah permainan bola voli melalui media balon (peserta didik kelas V SDN 13 Singkawang Barat).

\section{METODE PENELITIAN}

Penelitian ini menggunakan penelitian tindakan kelas (classroom action research) merupakan penelitian yang dilakukan oleh guru, yang mana guru dituntut untuk pada penyempurnaan atau peningkatan proses dan praktek pembelajaran yang ingin 
dilaksanakan. Dalam hal ini pendidik dapat memanfaatkan untuk pengembangan kurikulum, pengembangan metode pembelajaran, juga pengembangan dalam keahlian mendidik.

Metode penelitian tindakan kelas ini memiliki 4 langkah dalam melakukan penelitian hinggan mendapatkan hasil yang diinginkan oleh peneliti yaitu mulai dari perencanaan, kemudian melakukan pelaksanaan terhadap yang ingin diteliti, selanjutnya melakukan pengamatan pada hasil dan yang terakhir tahap refleksi. berdasarkan penjabaran diatas mengenai penelitian tindakan kelas yang mana peneliti merangkap juga untuk menjadi pengamat, maka dilaksanakannya pengamatan pada hasil peneltian dilakukan pada saat sudah terjadinya pelaksanaan dalam penelitian (Mulyatiningsih, 2019)

\section{HASIL DAN PEMBAHASAN}

Dalam menentukan hasil penelitian terlebih dahulu melakukan pre-tes. Hai ini berguna untuk mendapatkan data awal. Dalam hal ini, peneliti harus mengetahui pada tahap apa kemampuan peserta didik dalam melakukan pasing bahwa. Langkah selanjutnya terdapat hasil yang diperoleh pada saat pembelajaran pasing bawah yang dilakukan oleh peserta didik pada saat peneliti belum melakukan tindakan terhadap peserta didik untuk melakukan pasing bawah.

Diperolehnya hasil pre-implementasi pada pembelajaran pasing bawah pada permainan bola voli yang dilakukan oleh peserta didik agar memudahkan dalam melihat hasil data yang didapatkan setelah mendapatkan pembelajaran. Berikut terlihat pada tabel 1 dibawah ini.

Tabel 1. Rekapitulasi Hasil Nilai Pada Tes Awal

\begin{tabular}{lll}
\hline Ketuntasan & Jumlah peserta didik & Persentase \\
\hline Tuntas & 3 & $12 \%$ \\
\hline Belum tuntas & 22 & $88 \%$ \\
\hline Jumlah & 25 & $100 \%$ \\
\hline
\end{tabular}

Terlihat pada tabel 1. Bahwa data yang didapatkan menunjukan bahwa ketuntasan yang diperoleh peserta didik hanya 3 siswa/i dengan persentase $12 \%$. Kemudian peserta didik yang mendapatkan nilai belum tuntas sebanyak 22 siswa/i dengan persentase $88 \%$ dan dapat disimpulkan dari hasil diatas masih jauh dari indikator keberhasilan pembelajaran yang seharusnya. Hasil tindakan siklus I dalam bentuk mengetahui peningkatan setelah mendapatkan pembelajaran kemampuan pasing bawah pada permainan bola voli yang menggunakan balon/ bola karet yang lebih ringan guna untuk sebuah solusi untuk memperbaiki dan meningkatkan kemampuan pasing bawah.

Tabel 2 Rekapitulasi Hasil Siklus I

\begin{tabular}{lcc}
\hline Ketuntasan & Jumlah peserta didik & Persentase \\
\hline Tuntas & 16 & $64 \%$ \\
\hline Belum tuntas & 9 & $36 \%$ \\
\hline Jumlah & 25 & $100 \%$ \\
\hline
\end{tabular}

Dapat dilihat dari tabel 2. Bahwa sebanyak 16 peserta didik mendapatkan nilai tuntas pada saat melakukan pasing bawah dengan persentase $64 \%$. Kemudian terdapat 9 peserta didik dengan persentase $36 \%$ yang mendapatkan masih belum tuntas. Hal ini dapat dinilai sebagai keberhasilan metode pembelajaran permainan bola voli dalam memperbaiki nilai pasing bawah yang menggunakan balon, bola karet dianggap belum maksimal karena siswa masih belum memahami contoh yang diberikan guru, 
malas melakukan pengulangan-pengulangan, yang pasti masih menyisakan 9 peserta didik yang belum tuntas. Maka diperlukan refleksi dengan adanya penambahan perlakuan yang sama dapat dilakukan seorang guru, memberikan tambahan motivasi dan memberikan langkah-langkah teknik passing bawah secara detail agar menuntaskan seluruh peserta didik melalui tindakan pada siklus II. Hasil tindakan siklus II berdasarkan hasil evaluasi dari tindakan siklus I, dalam siklus II mendapatkan suatu peningkatan nilai peserta didik. Yang pada siklus I peserta didik mendapatkan nilai rata-rata 60 , di siklus II mendapatkan kembali peningkatan sebanyak $36 \%$. Berikut penjelasan melalui tabel dibawah ini:

Tabel 3 Rekapitulasi Nilai Hasil Belajar Peserta Didik Pada Siklus II

\begin{tabular}{ccccc}
\hline Ketuntasan & Jumlah peserta didik & Persentase & KKM & Nilai Rata-Rata \\
\hline Tuntas & 23 & $92 \%$ & 75 & 77 \\
\hline Belum tuntas & 2 & $8 \%$ & 75 & 69 \\
\hline Jumlah & 25 & $100 \%$ & 75 & 76,4 \\
\hline
\end{tabular}

Dalam tabel di atas terlihat bahwa peningkatan yang signifikan dengan hasil 92\% peserta didik mendapatkan nilai tuntas pada pembelajaran pasing bawah pada permainan bola voli pada siklus II dengan rata-rata nilai 77 . Yang belum tuntas hanya menyisakan 2 peserta didik yaitu sebesar $8 \%$ dengan rata-rata nilai 69. Dengan peningkatan ketuntasan Pada siklus I ke siklus II yaitu 7 peserta didik sebesar $28 \%$. dengan dengan persentase yang didapatkan yaitu $64 \%$ menjadi $92 \%$ pada siklus ke II dengan jumlah rata-rata nilai peserta didik sejumlah 76,4. Dengan metode pembelajaran siklus II yang menggunakan bola karet pada pelaksanaan permainan bola boli yang dilakukan peserta didik dapat disimpulkan berhasil.

\section{Pembahasan}

Permainan bola voli yang merupakan salah satu cabang olahraga yang cukup digandrungi oleh berbagai kalangan di Indonesia tidak terlepas dari perhatian ilmu pengetahuan guna untuk pengembangan pembelajaran yang lebih kreatif dengan memberikan beberapa sentuhan permainan yang lebih mudah dipahamai dan disukai oleh peserta didik.

Dalam pelaksanaan permainan bola voli harus dilakukan pembinaan sedini mungkin dan kreatif untuk peserta didik yang akan membentuk keterampilan teknik dasar yang mahir dan berprestasi pada permainan bola voli. Dengan dibantu oleh pembimbing, pelatih dalam pengembangan gerak dasar, skill permainan, pertumbuhan pengetahuan dalam memainkan permainan bola voli. Kreatifitas dalam memberi pengajaran sangatlah diperlukan, yang mana dapat terlihat dari hasil pre implementasi sampai siklus II. Dari awal hingga akhir memiliki nila yang berbeda-beda, diketahui pada saat pre implementasi peserta didik mencapai $88 \%$ mendapatkan nilai tidak tuntas. Yang dikarenakan model pembelajaran yang digunakan secara umum, artinya hanya dilakukan pembelajaran passing bawah tanpa ada tambahan model atau metode pembelajaran. Pada saat siklus I siswa banyak ditemukan belum mendapatkan ketuntasan yang besarannya 64\% dengan jumlah 16 peserta didik. Pada siklus I Siswa mendapatkan nilai kurang dari nilai KMM yaitu 75 karena kondisi pembelajaran kurang kondusif dan kurang maksimal(Wibowo, 2019a).

Pada siklus II yang mendapatkan nilai lebih dari nilai KKM yaitu 75 , keberhasilan atau nilai tuntas yang didapatkan peserta didik hingga $92 \%$ yang peserta didik dapatkan pada saat penilaian permainan bola voli pasing bawah yang menggunakan media tambahan yaitu media balon(Rajagukguk, 2017; Wibowo, 2019). Hasil penelitian ini diperkuat dengan penelitian yang dilakukan oleh (Yustal, 2017) yang mana menyatakan bahwa model permainan yang menggunakan balon/ bola karet dapat meningkatkan hasil pembelajaran asing bawah pada permainan bola voli.

Peserta didik dengan pembelajaran yang didapatkan, lebih memahami dengan 
cara menggunakan metode kreatif dari seorang pembimbing, pelatih dan pendidik. Dalam hal ini, dengan metode yang kreatif dan berbeda akan meningkatkan mutu mengajar pendidik dan meningkatkan motivasi dalam belajar serta mempercepat kemampuan khususnya materi passing bawah pembelajaran bola voli (Rajagukguk, 2017). Maka pendidik sangat perlu untuk mengikuti seminar keolahragaan dan juga mengikuti perkembangan zaman dalam pelaksanaan pembelajaran yang mana metode lama dan monoton sudah tidak lagi efektif digunakan untuk memberi pembelajaran terhadap peserta didik yang mana hal tersebut merupakan sebuah tanggungjawab seorang pendidik untuk memberikan pembelajaran yang kreatif.

\section{SIMPULAN}

Pada permainan bola voli yang diperuntukan untuk peserta didik tingkat dasar lebih cocok menggunakan media balon yang mana mudah untuk dilakukan pada pembelajaran bola voli khususnya pasing bawah. Dengan dimilikinya pendidik yang memiliki metode mengajar yang kreatif sangat dibutuhkan dan sangat berpengaruh dalam perkembangan peserta didik untuk mendapatkan ilmu pengetahuan dalam memainkan permainan bola voli.

Dari hasil yang signifikan mulai dari pre implementasi, siklus I hingga siklus II, dapat ditarik kesimpulan bahwa metode pembelajaran kreatif dapat memberikan dampak positif bagi peserta didik jika ingin meningkatkan pembelajaran bola voli dan meningkatkan motivasi belajar passing bawah pada pembelajaran bola voli. Dari yang menganggap hanya untuk olahraga saja hingga ke tahap yang serius untuk meraih prestasi melalui jalur atlet voli, maka diharuskan untuk mendapatkan pembelajaran yang benar sejak dini.

\section{DAFTAR PUSTAKA}

Faozi, F. dkk. (2019). Pengaruh Model Pembelajaran Kooperatif Tipe Stad Terhadap Keterampilan Passing Bawah Dalam Permainan Bola Voli Di SMA Islam Al-Fardiyatussa'adah Citepus
Palabuhanratu. Physical Activity

Journal, Vol. 1 .

Hambali, S. (2016). Pembelajaran Passing

Bawah Menggunakan Metode Bermain

Pada Permainan Bola Voli Siswa SD

Kelas V. Jurnal Pendidikan Olahraga, Vol. 5.

Mulyatiningsih, E. (2019). Metode Penelitian Tindakan Kelas. Ilmu Keolahragaan Nasional, Vol. 8.

Nanda Hanief, Y. (2018). Meningkatkan Hasil Belajar Passing Bawah Bolavoli melalui Permainan 3 on 3 pada Siswa Sekolah Dasar. Jurnal Pendidikan Jasmani Dan Olahraga, Vol. 2.

Olih Solihin, A. (2016). Profil Tingkat Motivasi Siswa Tunarungu Dalam Belajar Pendidikan Jasmani Adaptif. Jurnal Olahraga, Vol. 1 .

Rahmat, D. (2018). Pengaruh Pembelajaran Passing Berpasangan Terhadap Keterampilan Passing Bawah Dalam Permainan Bola Voli. Jurnal Olahraga, Vol. 2.

Rajagukguk, T. (2017). MENINGKATKAN

EFEKTIFITAS BELAJAR GERAK

DASAR PASSING BAWAH PADA PERMAINAN BOLA VOLLI DENGAN MENGGUNAKAN MEDIA MODIFIKASI BALON. SCHOOL EDUCATION JOURNAL PGSD FIP UNIMED, 7(4), 556-559. https://doi.org/10.24114/sejpgsd.v7i4.8 141

Setia Lengkana, A. (2017). Kebijakan Pendidikan Jasmani dalam Pendidikan. Jurnal Olahraga, Vol. 1.

Wibowo, G. W. (2019a). MENINGKATKAN PEMBELAJARAN PASSING BAWAH BOLA VOLI MENGGUNAKAN MEDIA BALON. Tajdidukasi: Jurnal Penelitian Dan Kajian Pendidikan Islam, 8(2). https://doi.org/10.47736/tajdidukasi.v8i 2.288 
Wibowo, G. W. (2019b).

MENINGKATKAN

PEMBELAJARAN PASSING

BAWAH BOLA VOLI

MENGGUNAKAN MEDIA BALON.

Tajdidukasi: Jurnal Penelitian Dan

Kajian Pendidikan Islam, 8(2).

https://doi.org/10.47736/tajdidukasi.v8i

2.288

Yustal. (2017). Model Bermain Balon Dalam Permainan Bola Voli Untuk

Meningkatkan Hasil Belajar Passing

Atas Siswa Kelas VIa SDN 21 Batang

Anai Kabupaten Padang Pariaman.

Jurnal Educatio, Vol. 3. 